\title{
Variações microclimáticas e perigo de ocorrência de incêndios florestais em fragmentos de Mata Atlântica no município de São Cristovão, Sergipe
}

\author{
Benjamin Leonardo Alves WHITE ${ }^{1 *}$, Maria Flaviane Almeida SILVA ${ }^{1}$ \\ ${ }^{1}$ Universidade Federal de Sergipe, São Cristovão, SE, Brasil. \\ *E-mail: benjmk@hotmail.com
}

Recebido em outubro/2017; Aceito em agosto/2018.

RESUMO: Clareiras, sejam elas naturais ou decorrentes de atividades antrópicas, alteraram as condições microclimáticas do ambiente que, por sua vez, afetam a sobrevivência da fauna e a susceptibilidade à ocorrência de incêndios florestais. Este estudo teve como objetivo mensurar as variações microclimáticas em uma área bem conservada e em uma clareira de quatro hectares localizadas no interior de fragmento de Mata Atlântica no município de São Cristóvão, Sergipe. Também buscou-se determinar qual o perigo de ocorrência de incêndios florestais em ambas as áreas. Para tal, foram utilizados sensores acoplados com data loggers, programados para registrarem os dados de temperatura do ar, umidade relativa do ar e temperatura do solo a cada 10 minutos durante o período de um ano. O índice de Angstron foi utilizado para determinar o perigo de ocorrência de incêndios florestais. Os resultados apontaram um incremento de $1,3^{\circ} \mathrm{C}$ na temperatura média do ar; $3,6^{\circ} \mathrm{C}$ na temperatura média do solo; e, uma redução de $10,2 \%$ na umidade relativa do ar média ocasionados pela abertura da clareira. O microclima na vegetação conservada foi mais estável. Gráficos das variáveis mensuradas foram plotados a fim de verificar as variações diárias e anual. As variações microclimáticas resultantes da abertura da clareira foram responsáveis por incremento no perigo de ocorrência de incêndios florestais.

Palavras-chave: incêndios florestais, meteorologia, clareiras.

\section{Microclimate variations and fire danger in an Atlantic Forest fragment in the municipality of São Cristóvão, Sergipe}

\begin{abstract}
Forest gaps, whether natural or caused by human activities, alter the microclimatic conditions, which, in turn, affect wildlife survival and susceptibility to forest fires. The objective of this study was to measure the microclimatic variations between a 4-hectare gap and a well-conserved closed-canopy area, both located in an Atlantic Forest fragment in the municipality of São Cristóvão, Sergipe, Brazil. The differences in the fire danger in both areas was also assessed. For this purpose, sensors coupled with datalogger were used to record air temperature, air relative humidity and soil temperature every 10 minutes during the period of one year. The Angstron index was used to determine the fire danger. The results indicated an increase in the gap of $1.3^{\circ} \mathrm{C}$ in the average air temperature; $3.6^{\circ} \mathrm{C}$ in the average soil temperature; and a reduction of $10.2 \%$ in the average air humidity. The microclimate in the closed forest was more stable. Profiles for the variables measured were plotted to verify variations throughout the day and the year. The microclimatic variations caused by the gap were responsible for an increase in the fire danger.
\end{abstract}

Keywords: forest fires, meteorology, forest gaps.

\section{INTRODUÇÃO}

A fragmentação das florestas resulta na perturbação dos habitats naturais, levando à alteração dos nichos e do microclima, culminando assim, com a redução da disponibilidade de alimento, de espaço e de abrigo para algumas das espécies que ali vivem. Redução dos grupos especialistas, queda no fluxo gênico de espécies vegetais e animais, segregação, isolamento de habitats e aumento da borda também são algumas consequências resultantes da fragmentação florestal (ROSENZWEIG, 1995; CÔRREA; LOUZADA, 2010; TABARELLI et al., 2010).

As bordas são unidades da paisagem que alteram os fluxos biológicos de forma brusca em decorrência de mudanças abióticas entre matriz e fragmento. Essas mudanças abióticas na interação entre paisagens distintas são denominadas efeito de borda, e geralmente resultam no aumento da penetração da luz solar no interior do fragmento
(LAURANCE; YENSEN, 1991; MILAN et al., 2016). Essa maior intensidade de raios solares pode levar ao aumento da temperatura, e, consequentemente, elevar a ocorrência de ventos e da evapotranspiração (KAPOS, 1989; LAURANCE; YENSEN, 1991). De acordo com Kapos (1989), os efeitos de borda podem ser sentidos a 40 metros de distância da borda adentro do fragmento. Alves Júnior et al. (2006) relatam que a partir de 100 metros adentro do fragmento, os efeitos da borda sobre a vegetação são minimizados.

Atividades antrópicas em ecossistemas naturais, como a prática da agricultura, pecuária e silvicultura, por exemplo, alteram os padrões de incidência de radiação solar, temperatura, umidade e vento, alterando assim as características microclimáticas do ambiente alterado. Além dos efeitos locais provocados por esses tipos de atividades, as bordas dos ecossistemas florestais remanescentes terão sua densidade e composição das comunidades animais e vegetais 
alteradas, o que pode ocasionar diversos desequilíbrios como: alterações na riqueza, diversidade, abundância, mortalidade, dinâmica sucessional, densidade populacional, dentre outros (TABARELLI et al., 2010; MAGURA et al., 2017).

As condições microclimáticas e vegetacionais alteradas a partir do desmatamento e abertura de clareiras em ecossistemas florestais pode resultar no aumento da ocorrência de incêndios florestais. A remoção da cobertura arbórea resulta no estabelecimento de espécies pioneiras, a exemplo de gramíneas do gênero Brachiaria, que propagam o fogo com maior facilidade (WHITE et al., 2013; WHITE et al., 2017)

Para se determinar o perigo de ocorrência de incêndios florestais existem índices que, baseando-se em variáveis climáticas medidas diariamente, determinam se as condições meteorológicas estão propícias ou não para a ocorrência de incêndios florestais (SOARES; BATISTA, 2007; WHITE; RIBEIRO, 2010). Dentre os existentes na literatura, o índice de Angstron, desenvolvido na Suécia na década de 80, se destaca pela sua eficiência e simplicidade (SOARES; BATISTA, 2007; WHITE; RIBEIRO, 2010; WHITE et al., 2015).

Em função da importância que o microclima exerce na biota, o presente estudo teve por objetivo analisar as variações microclimáticas das temperaturas do ar e do solo, e umidade relativa do ar, em duas distintas áreas dentro de um fragmento de Mata Atlântica de Tabuleiro: em uma área bem conservada de dossel fechado e em uma clareira. Além disso, verificou-se qual a influência que o microclima exerce no perigo de ocorrência de incêndios florestais em ambas áreas de estudo.

\section{MATERIAL E MÉTODOS}

\subsection{Caracterização da área de estudo}

O estudo foi realizado em um fragmento florestal situado no Campus do Instituto Federal de Sergipe (IFS), localizado no povoado Quissamã, município de São Cristóvão, Sergipe, Brasil. A área tem um clima tropical, com a estação chuvosa durante o inverno. De acordo com a classificação de KöppenGeiger o clima da região é do tipo AS. As maiores temperaturas são registradas no mês de fevereiro, enquanto as menores em julho.

A área ocupada pelo fragmento florestal de Mata Atlântica de Tabuleiro é de aproximadamente 450 hectares, estando algumas áreas em estado de sucessão secundária e outras, mais conservadas, em estágios sucessionais tardios.

\subsection{Coleta e Análise dos Dados}

Uma das estações meteorológicas (Misol WS-DS100-1 data logger) foi instalada nas coordenadas 10 $10^{\circ}$ '57'S e $37^{\circ} 11$ '52'W com altitude de 46 metros, no interior do fragmento florestal, em uma das áreas em melhor estado de conservação com copa densa e fechada, distando cerca de 500 metros da borda mais próxima. A segunda estação, do mesmo modelo, foi instalada a 650 metros de distância da primeira, em uma clareira de 4 hectares com ausência de cobertura arbórea, situada no interior do fragmento florestal nas coordenadas $10^{\circ} 54^{\prime} 18^{\prime \prime} \mathrm{S}$ e $37^{\circ} 11^{\prime} 53^{\prime \prime} \mathrm{W}$, com altitude de 40 metros (Figura 1).

A temperatura do solo foi mensurada com auxílio de dois termômetros (R1B1 data logger) com seus sensores externos enterrados a $2 \mathrm{~cm}$ de profundidade em ambas as áreas avaliadas. O solo da mata fechada no ponto de amostragem estava recoberto por aproximadamente 3 centímetros de serapilheira. $\mathrm{Na}$ clareira, o solo estava revestido por gramíneas pioneiras com altura inferior a $5 \mathrm{~cm}$. Importante frisar que todos os equipamentos foram previamente calibrados antes de serem instalados em campo.

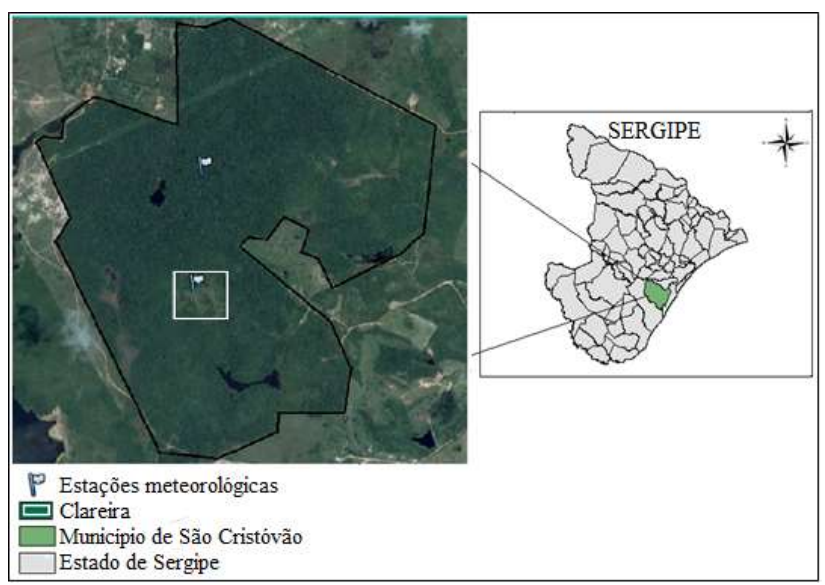

Figura 1. Fragmento florestal de Mata Atlântica de Tabuleiro no Campus do Instituto Federal de Sergipe, São Cristóvão, Sergipe.

Figure 1. Atlantic Forest fragment in the Federal Institute of Sergipe Campus, São Cristóvão, Sergipe, Brazil.

Os dados de temperatura do ar, umidade relativa do ar e temperatura do solo foram programados a serem registrados a cada 10 minutos. Os resultados do presente trabalho foram baseados em dados registrados de outubro de 2015 até o final de setembro de 2016, perfazendo um total de 365 dias.

Os dados armazenados nas estações foram transferidos para um microcomputador, mensalmente, e analisados com auxílio do software JMP Statistical Package (versão 10.0; SAS Institute, Cary, NC).

A análise de variância (ANOVA) foi utilizada para verificar a existência de diferença significativa entre os dados registrados no interior da mata e na clareira. Valores médios, máximos e mínimos também foram definidos para posterior comparação e discussão.

\subsection{Análise do perigo de ocorrência de incêndio florestal}

Foi utilizado o índice de Angstron com o objetivo de verificar o perigo de ocorrência de incêndios florestais na mata fechada e na clareira. O respectivo índice foi utilizado em função de não ser cumulativo e de utilizar apenas duas variáveis climáticas: temperatura e umidade relativa do ar (Equação 1).

$$
B=0,05 * H-\left(\frac{T-27}{10}\right)
$$

(Equação 1)

em que: $B=$ índice de Angstron; $H=$ umidade relativa do ar em \%; $T=$ temperatura do ar em ${ }^{\circ} \mathrm{C}$.

A interpretação do índice é feita da seguinte maneira: sempre que o valor de "B" for menor do que 2,5 haverá perigo de incêndios, isto é, as condições atmosféricas do dia estarão favoráveis à ocorrência de incêndios (WHITE; RIBEIRO, 2010).

O índice foi utilizado em quatro diferentes cenários: utilizando os parâmetros médios de temperatura e umidade relativa do ar obtidos ao longo de um ano; utilizando os percentis de $75 \%$; utilizando os percentis de $90 \%$; e, por fim, utilizando-se os valores extremos. A realização de simulações 
utilizando os percentis de $75 \%, 90 \%$ e os valores mais extremos se deve ao fato de que, ao se analisar o perigo de ocorrência de incêndios florestais deve-se levar em consideração não apenas os parâmetros meteorológicos médios para uma determinada região, mas, principalmente, os valores extremos (WHITE et al., 2013; WHITE et al., 2014).

\section{RESULTADOS}

3.1. Variação média

A temperatura do ar média anual na área de mata fechada foi de $25,3^{\circ} \mathrm{C}$, enquanto que na área de clareira foi de $26,6^{\circ} \mathrm{C}$ $(\mathrm{F}=2219,48 ; \mathrm{p}<0,001)$. A umidade relativa do ar, por sua vez, apresentou valor médio anual de $83,4 \%$ na área de mata e $73,2 \%$ na clareira $(F=6701,97 ; p<0,001)$. A temperatura média anual do solo na mata fechada foi de $25,5^{\circ} \mathrm{C}$ enquanto na clareira foi de $29,1^{\circ} \mathrm{C}(\mathrm{F}=14477,1 ; \mathrm{p}<0,001)$. Os valores de todas as variáveis analisadas foram significativamente diferentes quando comparados entre a clareira e a mata fechada utilizando-se o teste ANOVA.

O microclima na vegetação conservada foi mais estável ao longo do ano, apresentando uma variação de $14,5^{\circ} \mathrm{C}$ entre os valores máximo e mínimo da temperatura do ar, uma variação de $10^{\circ} \mathrm{C}$ entre a temperatura do solo máxima e mínima, e uma variação de $53 \%$ entre a umidade relativa do ar máxima e mínima. Na clareira, esses valores foram de, respectivamente, $19,3^{\circ} \mathrm{C}, 30,7^{\circ} \mathrm{C}$ e $65 \%$ (Tabela 1 ).

Tabela 1. Valores médios, máximos e mínimos da temperatura do ar, temperatura do solo e umidade relativa do ar para cada área de estudo definidos ao longo de um ano.

Table 1. Mean, maximum and minimum values of air temperature, soil temperature and air humidity for each study site evaluated during one year.

\begin{tabular}{lcc}
\hline \multicolumn{1}{c}{ Variável } & Clareira & Mata fechada \\
\hline Temperatura do ar média & $26,6^{\circ} \mathrm{C}( \pm 4,99)$ & $25,3^{\circ} \mathrm{C}( \pm 3,06)$ \\
Temperatura do ar máxima & $37,4^{\circ} \mathrm{C}$ & $33,7^{\circ} \mathrm{C}$ \\
Temperatura do ar mínima & $18,1^{\circ} \mathrm{C}$ & $19,2^{\circ} \mathrm{C}$ \\
Temperatura do solo média & $29,1^{\circ} \mathrm{C}( \pm 6,21)$ & $25,5^{\circ} \mathrm{C}( \pm 2,03)$ \\
Temperatura do solo máxima & $50,8^{\circ} \mathrm{C}$ & $31,6^{\circ} \mathrm{C}$ \\
Temperatura do solo mínima & $20,1^{\circ} \mathrm{C}$ & $21,6^{\circ} \mathrm{C}$ \\
Umidade relativa do ar média & $73,2 \%( \pm 20,58)$ & $83,4 \%( \pm 13,63)$ \\
Umidade relativa do ar máxima & $97 \%$ & $99 \%$ \\
Umidade relativa do ar mínima & $32 \%$ & $46 \%$ \\
\hline
\end{tabular}

*Nota: $\pm=$ Desvio Padrão.

\subsection{Variação mensal}

O mês de Janeiro de 2016 foi o mais quente durante o período avaliado, apresentando temperatura do ar média de $28,3^{\circ} \mathrm{C}$ e $26,7^{\circ} \mathrm{C}$ para a área de clareira e mata fechada, respectivamente. Já o mês mais frio foi o de Agosto, apresentando temperatura do ar média de $23,9^{\circ}$ na clareira e $23,1^{\circ} \mathrm{C}$ na mata fechada. As maiores diferenças entre as temperaturas do ar de ambas as áreas de estudo foram verificadas durante os meses mais quentes (Novembro a Março), apresentando uma diferença média de $1,5^{\circ} \mathrm{C}$. Já nos meses mais frios a variação da temperatura média do ar foi um pouco inferior, apresentando um valor próximo $1,0^{\circ} \mathrm{C}$ nos meses de maio, junho, julho e agosto. Considerando todo o período avaliado, a diferença da temperatura média do ar entre ambas as áreas de estudo foi de $1,3^{\circ} \mathrm{C}$ (Figura 2 ).

A variação anual da temperatura do solo foi bem semelhante à variação observada na temperatura do ar. $\mathrm{O}$ mês que apresentou a maior temperatura média foi o de Janeiro $\left(32,8^{\circ} \mathrm{C}\right.$ na clareira e $27,2^{\circ} \mathrm{C}$ na mata fechada), enquanto que as menores temperaturas foram registradas no mês de
Agosto, apresentando valor médio de $24,2^{\circ} \mathrm{C}$ na clareira e $23,1^{\circ} \mathrm{C}$ na mata fechada. As maiores diferenças entre as temperaturas do solo de ambas as áreas de estudo também foram verificadas durante os meses mais quentes (Novembro a Março). No mês de Janeiro, por exemplo, a diferença média entre ambas as áreas foi de $5,5^{\circ} \mathrm{C}$. Nos meses mais frios essa variação foi observada em menor intensidade. No mês de Agosto, por exemplo, a diferença foi de $1,1^{\circ} \mathrm{C}$. Considerando todo o período avaliado, a diferença entre as médias da temperatura do solo na clareira e na mata fechada foi de $3,6^{\circ} \mathrm{C}$ (Figura 3 ).

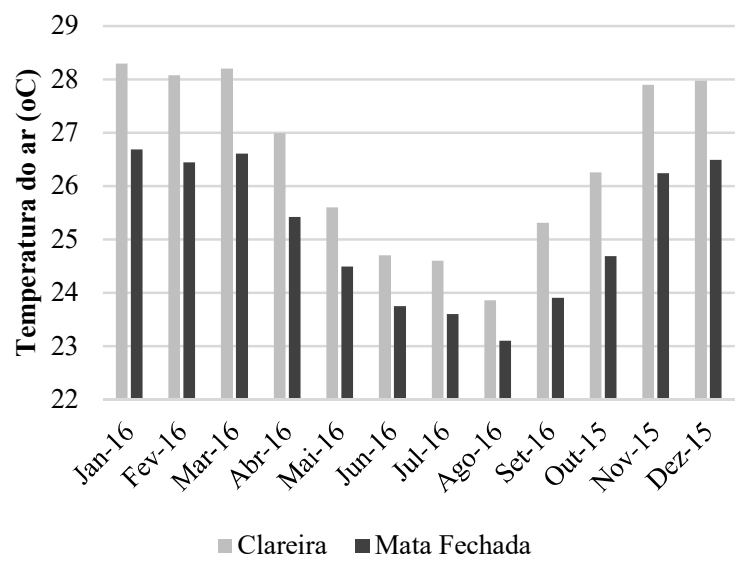

Figura 2. Variação média mensal da temperatura do ar na clareira e na mata fechada mensurada, durante o período de um ano, em fragmento de Mata Atlântica no município de São Cristóvão, Sergipe, Brasil.

Figure 2. Average monthly air temperature variation in the gap and in the closed forest measured during the period of one year in an Atlantic Forest fragment located in the municipality of São Cristóvão, Sergipe, Brazil.

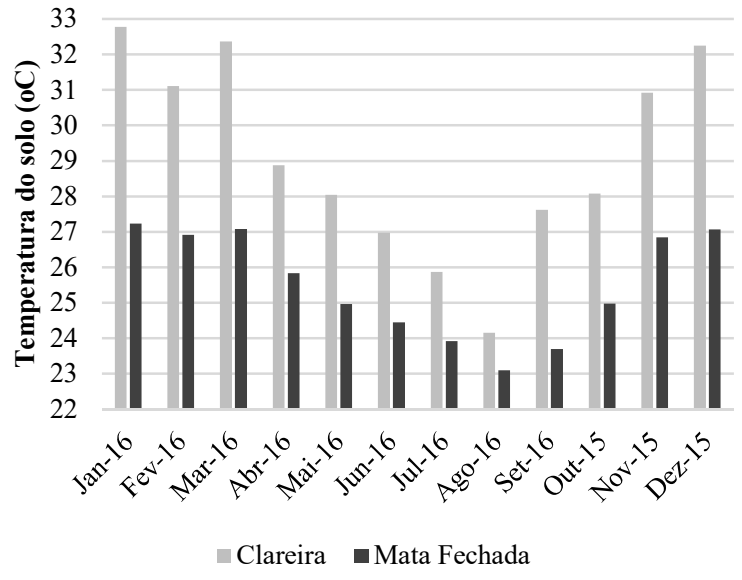

Figura 3. Variação média mensal da temperatura do solo na clareira e na mata fechada mensurada, durante o período de um ano, em fragmento de Mata Atlântica no município de São Cristóvão, Sergipe, Brasil.

Figure 3 . Average monthly soil temperature variation in the gap and in the closed forest measured during the period of one year in an Atlantic Forest fragment located in the municipality of São Cristóvão, Sergipe, Brazil.

Em se tratando da umidade relativa do ar, o mês em que os menores valores foram registrados foi Novembro, apresentando valor médio de $77,5 \%$ na área de mata fechada 
e $69,2 \%$ na clareira. Já o mês que apresentou os maiores valores em ambas as áreas avaliadas foi Junho, com valor médio de $80,4 \%$ na clareira e $91,3 \%$ na mata fechada. A diferença entre o valor médio de ambas as áreas durante o período avaliado foi de 10,2\% (Figura 4).

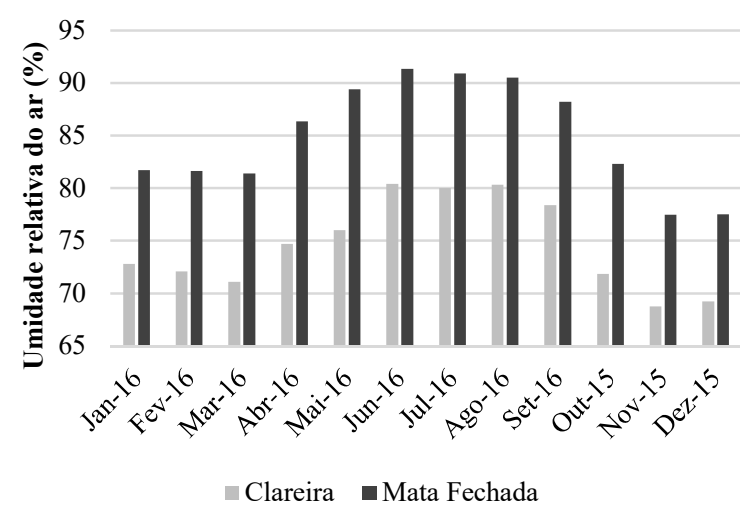

Figura 4. Variação média mensal da umidade relativa do ar na clareira e na mata fechada mensurada, durante o período de um ano, em fragmento de Mata Atlântica no município de São Cristóvão, Sergipe, Brasil.

Figure 4. Average monthly air relative humidity variation in the gap and in the closed forest measured during the period of one year in an Atlantic Forest fragment located in the municipality of São Cristóvão, Sergipe, Brazil.

\subsection{Variação diária}

Com base nos dados de temperatura do ar obtidos ao longo de 365 dias, foi traçado o perfil médio diário para ambas as áreas de estudo. Os valores máximos da temperatura do ar foram registrados entre as 12:30 e 13:30 (média anual de $33,1^{\circ} \mathrm{C}$ na clareira e $29,4^{\circ} \mathrm{C}$ na mata fechada), enquanto os valores mínimos aproximadamente às 05:30 para ambas as áreas avaliadas (média anual de $21,5^{\circ} \mathrm{C}$ na clareira e $22,3^{\circ} \mathrm{C}$ na mata fechada). Próximo de $6: 00$ da manhã ambas as áreas apresentam a mesma temperatura do ar, no entanto, na clareira a temperatura aumenta mais rapidamente, permanecendo superior à temperatura da área de mata fechada até aproximadamente às 18:30. Após este horário a temperatura do ar na clareira se torna inferior à da mata fechada e continua inferior até, aproximadamente, 1 hora após o nascer do sol que acontece, com maior frequência ao longo do ano, por volta de 05:30 da manhã (Figura 5).

A temperatura do solo apresentou valores máximos com maior frequência por volta das 13:30 na clareira (média anual de $39,6^{\circ} \mathrm{C}$ ). Na mata fechada os valores mais altos foram registrados entre as 13 e as 15 horas (média anual de $26,8^{\circ} \mathrm{C}$ ), não havendo diferença significativa entre os valores da temperatura do solo da mata fechada nesse intervalo de tempo $(\mathrm{F}=0,28 ; \mathrm{p}=0,84)$. Os valores mínimos foram registrados às 5:30 na clareira (média anual de $24,4^{\circ} \mathrm{C}$ ) e entre 4 e 7 horas na mata fechada (média anual de $24,2^{\circ} \mathrm{C}$ ), também não havendo diferença significativa entre os valores da temperatura do solo da mata fechada nesse intervalo de tempo $(F=0,31 ; p=0,73)$. Os valores médios da temperatura do solo na clareira ao longo do dia foram todos superiores à temperatura na mata fechada. Os valores mais próximos foram registrados por volta de 5:30 da manhã, havendo uma diferença não significativa $(F=2,0 ; p=0,11)$ de apenas $0,2^{\circ} \mathrm{C}$ entre ambas as áreas. A variação média da temperatura do solo na mata fechada ao longo do dia foi de apenas $2,63^{\circ} \mathrm{C}$, enquanto que na clareira foi de $15,22^{\circ} \mathrm{C}$ (Figura 6).

Os valores médios da variação diária da umidade relativa demonstram que os valores mínimos na clareira foram verificados por volta das 12:30 (média anual de 47,2\%), enquanto que na mata fechada, por volta das 13:30 (média anual de $66,3 \%$ ). Os valores máximos da umidade relativa do ar na clareira foram registrados mais frequentemente às 5:30 (média anual de 93,9\%) e na mata fechada às 6:30 (média anual de 93,6\%). Enquanto que a umidade relativa do ar na clareira decresce rapidamente após às 5:30, ou seja, com o nascer do sol, na mata ela permanece bastante elevada e começa a decrescer com maior intensidade apenas após às 7:30. Após às 15:30, a umidade passa a subir rapidamente na clareira e de forma mais lenta na mata fechada. Por volta de meia noite, a umidade relativa do ar na clareira se torna levemente superior à da mata fechada e permanece desta forma até o nascer do sol por volta das 5:30 da manhã (Figura 7).

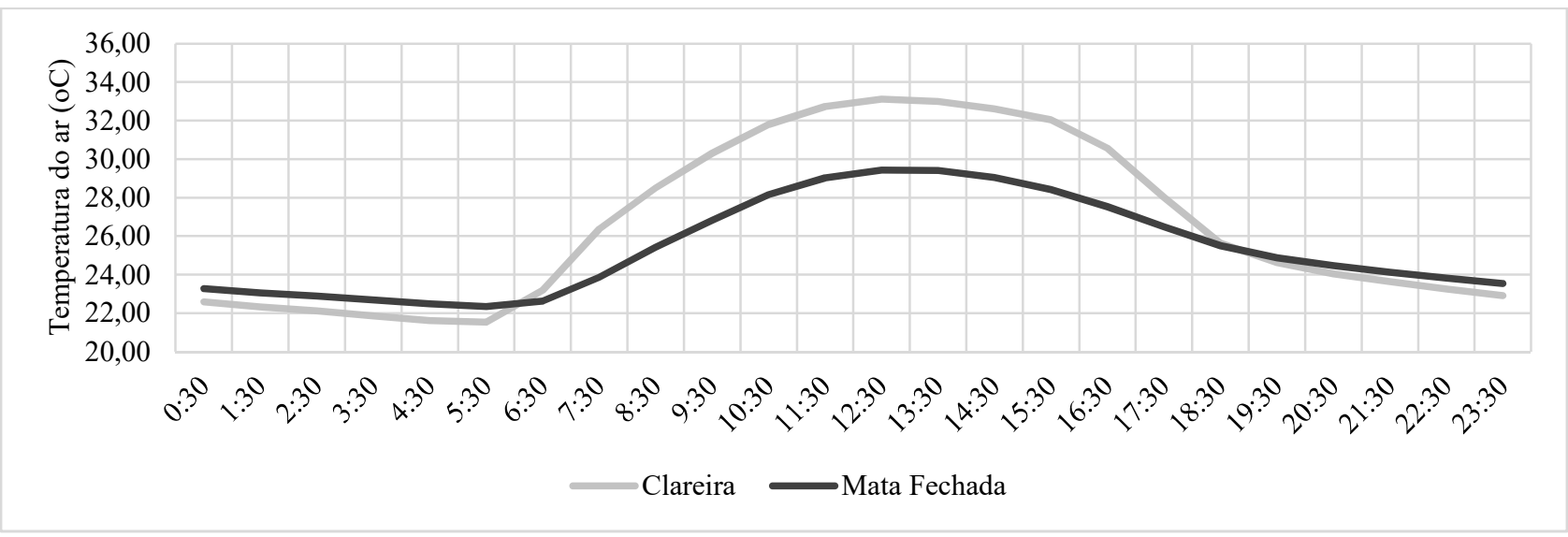

Figura 5. Variação da temperatura do ar ao longo do dia com base em valores médios mensurados durante um ano (01/10/2015 30/09/2016) na clareira e na mata fechada de um fragmento de Mata Atlântica no município de São Cristóvão, Sergipe, Brasil. Figure 5. Variation of air temperature throughout the day based on mean values measured during one year $(10 / 01 / 2015-09 / 30 / 2016)$ in the gap and in the closed forest of an Atlantic Forest fragment located in the municipality of São Cristóvão, Sergipe, Brazil. 


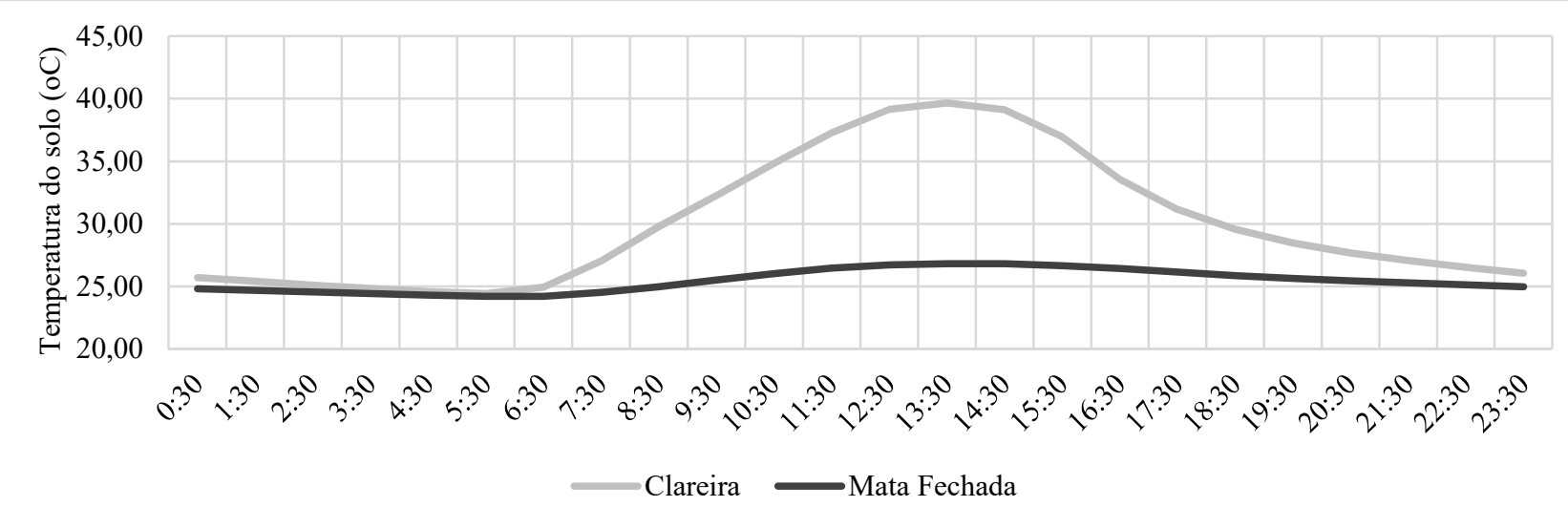

Figura 6. Variação da temperatura do solo ao longo do dia com base em valores médios mensurados durante o período de um ano (01/10/2015 - 30/09/2016) na clareira e na mata fechada de um fragmento de Mata Atlântica no município de São Cristóvão, Sergipe, Brasil.

Figure 6. Variation of soil temperature throughout the day based on mean values measured during one year $(10 / 01 / 2015-09 / 30 / 2016)$ in the gap and in the closed forest of an Atlantic Forest fragment located in the municipality of São Cristóvão, Sergipe, Brazil.

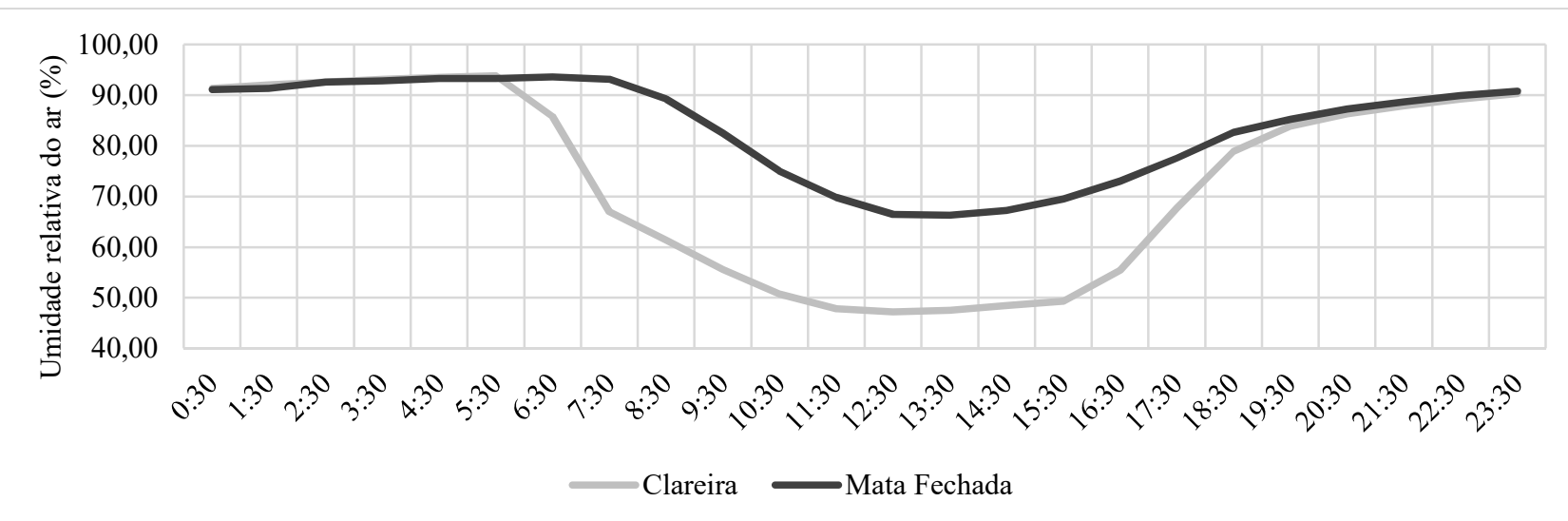

Figura 7. Variação da umidade relativa do ar ao longo do dia com base em valores médios mensurados durante o período de um ano (01/10/2015 - 30/09/2016) na clareira e na mata fechada de um fragmento de Mata Atlântica no município de São Cristóvão, Sergipe, Brasil.

Figure 7. Variation of air relative humidity throughout the day based on mean values measured during one year (10/01/2015 - 09/30/2016) in the gap and in the closed forest of an Atlantic Forest fragment located in the municipality of São Cristóvão, Sergipe, Brazil.

\subsection{Análise do perigo de ocorrência de incêndios florestais}

Para a realização das simulações utilizando o índice de Angstron em quatro diferentes cenários foi necessário, inicialmente, definir os valores médios; os percentis de $75 \%$ e de $90 \%$; e, os valores extremos da temperatura e umidade relativa do ar (Tabela 2).

Tabela 2. Valores médios, percentis de $75 \%$ e $90 \%$ e valores extremos da temperatura e umidade relativa do ar obtidos ao longo de um ano na área de clareira e de mata fechada.

Table 2. Mean values, percentiles of $75 \%$ and $90 \%$ and extreme values of temperature and air humidity obtained during one year period in the gap and in the closed forest.

\begin{tabular}{ccccc}
\hline \multirow{2}{*}{ Valor } & \multicolumn{2}{c}{$\begin{array}{c}\text { Temperatura do ar } \\
\left({ }^{\circ} \mathrm{C}\right)\end{array}$} & \multicolumn{2}{c}{$\begin{array}{c}\text { Umidade relativa do } \\
\text { ar }(\%)\end{array}$} \\
\cline { 2 - 5 } & Clareira & $\begin{array}{c}\text { Mata } \\
\text { Fechada }\end{array}$ & Clareira & $\begin{array}{c}\text { Mata } \\
\text { Fechada }\end{array}$ \\
\hline Médio & 26,6 & 25,3 & 73,2 & 83,4 \\
Percentil 75\% & 31,1 & 27,3 & 53.3 & 74.8 \\
Percentil 90\% & 34,3 & 29,9 & 43,8 & 62 \\
Extremo & 37,4 & 33,7 & 32 & 46 \\
\hline
\end{tabular}

Com base nas simulações, percebe-se o maior perigo de ocorrência de incêndios florestais, em todos os cenários avaliados, na área de clareira. A área de mata fechada apresentou perigo de ocorrência de incêndio florestal apenas na simulação com os valores extremos, enquanto na clareira as simulações utilizando-se os percentis de $75 \%$ e $90 \%$ também apresentaram perigo (Tabela 3).

Tabela 3. Valores do índice de Angstron nos quatros distintos cenários para a área de clareira e de mata fechada.

Table 3. Angstrom index values in the four distinct scenarios for the gap and closed forest areas.

\begin{tabular}{ccc}
\hline \multirow{2}{*}{ Cenário } & \multicolumn{2}{c}{ Valor do índice de Angstron $(B)$} \\
\cline { 2 - 3 } & Clareira & Mata Fechada \\
\hline Valores médios & 3,7 & 4,34 \\
Percentil $75 \%$ & $\underline{2,26}$ & 3,71 \\
Percentil $90 \%$ & $\underline{1,46}$ & 2,81 \\
Valores extremos & $\underline{0,56}$ & $\underline{1,63}$ \\
\hline
\end{tabular}

*Nota: Valores sublinhados apresentam perigo de ocorrência de incêndios florestais $(B<2,5)$.

\section{DISCUSSÃO}

As variações microclimáticas observadas neste estudo entre a área de mata fechada e a área de clareira estão bem próximas de estudos similares realizados em áreas de Mata 
Atlântica. Júnior (2012), por exemplo, ao avaliar cinco distintas áreas em diferentes níveis de conservação e antropização ao longo do rio Peruaçu, MG, afirma que o ambiente mais alterado teve um incremento na temperatura do ar média de $1,3^{\circ} \mathrm{C}$ e uma redução na umidade relativa do ar média de 5\% quando comparado com a mata ciliar conservada. Em uma antiga área de floresta que foi convertida em pastagem no Norte do Pantanal, Biudes et al., (2012) afirmam que esta conversão ocasionou uma diminuição de $5,7 \%$ da umidade relativa do ar e aumento de aproximadamente $1^{\circ} \mathrm{C}$ na média da temperatura máxima do ar. Além disso, os mesmos autores relatam uma diminuição de $16 \%$ do volume de precipitação pluviométrica na área após a conversão da floresta em pastagem. Em estudo realizado na Bacia do Rio Itapemirim, ES, Martineli et al. (2004) verificaram que a média da temperatura do ar na área de dossel fechado foi de $24,6^{\circ} \mathrm{C}$, enquanto que em uma pequena clareira foi de $25,6^{\circ} \mathrm{C}$, resultando assim, em uma diferença de $1^{\circ} \mathrm{C}$ entre ambas as áreas de estudo. Com relação à umidade relativa do ar, os autores afirmam que nenhuma mudança significativa foi observada.

Embora a grande maioria dos estudos apontem um incremento similar (entre 1 e $1,3^{\circ} \mathrm{C}$ ) na temperatura média do ar decorrente da retirada da vegetação arbórea, a variação dos valores da umidade relativa do ar não costuma ser tão homogênea. É certo que áreas que apresentam vegetação arbórea possuem maiores taxas de evapotranspiração, o que contribui com o aumento da umidade relativa do ar. Todavia, o processo de saturação, as características da variação de umidade e os grandes erros de medição, tornam o problema de contraste do conteúdo de vapor d'água no ambiente mais complexo do que para a temperatura (FORTUNIAK et al., 2006).

A variação da temperatura do solo nas camadas mais superficiais entre áreas com e sem cobertura arbórea costuma ser mais intensa que a variação da temperatura do ar (GASPARIM et al., 2005). Em uma floresta estacional semidecídua em Viçosa, MG, Pezzopane et al. (2005) concluíram que a temperatura do solo a $2 \mathrm{~cm}$ de profundidade foi, em média, $5,6^{\circ} \mathrm{C}$ menor no interior da floresta do que na área aberta adjacente. MARTINELI et al. (2004) na Bacia do Rio Itapemirim, ES, ao avaliarem a temperatura do solo também a $2 \mathrm{~cm}$ de profundidade, obtiveram um valor médio de $23,7^{\circ} \mathrm{C}$ para a área de dossel fechado e $26,7^{\circ} \mathrm{C}$ na clareira.

Dentre as variáveis microclimática avaliadas neste estudo, a temperatura do solo a $2 \mathrm{~cm}$ de profundidade foi a que, proporcionalmente, apresentou maior diferença em ambas as áreas avaliadas, sendo seu valor médio $14,1 \%$ superior na clareira. Acontece que em uma área sem cobertura vegetal, com o solo diretamente exposto ao sol, grande parte da radiação solar direta é absorvida pelas camadas mais superficiais do solo, resultando em valores de temperatura maiores que a temperatura do ar (ALVALÁ et al., 2002). É importante frisar que em maiores profundidades, a variação da temperatura do solo entre áreas com e sem cobertura arbórea costuma ser inferior (CARNEIRO et al., 2014). Além disso, características do solo como seu teor de umidade, composição e estrutura também interferem na sua temperatura (ALVALÁ et al., 2002).

Temperaturas mais altas e menor conteúdo de vapor d'água no ambiente deixam o material vegetal mais seco e, consequentemente, com maior facilidade de entrar em processo de ignição (SOARES; BATISTA, 2007; WHITE et al., 2016). Sendo assim, a abertura de clareiras em uma floresta eleva o perigo de ocorrência de incêndios florestais, que de acordo com White; Ribeiro (2011), constituem uma das maiores ameaças aos reflorestamentos e florestas nativas do planeta, causando bilhões de dólares em prejuízo todos os anos. $\mathrm{O}$ aumento no registro de incêndios florestais no Brasil nas últimas décadas, inclusive em áreas de Floresta Tropical e Mata Atlântica, está intimamente relacionado com a constante fragmentação dos ecossistemas florestais, proporcionado assim, condições microclimáticas mais favoráveis à propagação do fogo (WHITE et al., 2017).

Estudos desenvolvidos nos últimos anos utilizando-se de diferentes índices de perigo de ocorrência de incêndios florestais, apontam que o índice de Angstron apresentou boa eficiência, quando comparado com os demais testados, em prever a ocorrência de incêndios florestais no Nordeste Brasileiro (WHITE; RIBEIRO, 2011; WHITE et al., 2015). Sendo assim, a elevação do perigo de ocorrência de incêndios florestais provocada pela abertura da clareira na área de estudo, justifica a necessidade de se conservar e evitar a fragmentação dos ecossistemas florestais a fim de se reduzir a ocorrência de incêndios florestais e, consequentemente, reduzir os danos ambientais provocados pelo fogo.

As condições microclimáticas mais amenas e estáveis encontradas no interior de uma floresta se devem ao fato da vegetação atuar como um regulador de temperatura e umidade. Em áreas de florestas, durante o dia a temperatura no sub-bosque será inferior à de áreas sem cobertura vegetal, uma vez que as copas, os galhos e os troncos das árvores atuam como barreira da radiação solar direta, e, assim, é reduzida a disponibilidade de energia para aquecer o ar e o solo. Portanto, a densidade do dossel e a altura da vegetação irão interferir no fluxo de calor (HARPER, 2005). Além disso, a vegetação permite que os processos de infiltração d'água no solo sejam mais eficientes. Desta forma, ocorre o aumento da capacidade do solo de transmitir o calor absorvido, retardando o tempo de aquecimento do ar. A serapilheira também exerce papel fundamental em se tratando da temperatura do ar e do solo. A mesma atua como um isolante térmico, dificultando a troca de energia entre soloatmosfera, mantendo a sua temperatura estável com pequenas variações ao longo do dia (MENDONÇA; DANNIOLIVEIRA, 2007; RODRIGUES et al., 2010; CARNEIRO et al., 2014).

Em se tratando de variações sazonais e diárias, são poucos os estudos que fazem essa caracterização com um nível de detalhamento aprofundado. Carneiro et al. (2014) ao avaliarem a temperatura do solo em remanescente de Mata Atlântica em Coruripe, AL, afirmam que a temperatura mínima do solo é registrada no fim da madrugada e início da manhã, com valores médios de $20,7^{\circ} \mathrm{C}$ entre 4 e $7 \mathrm{~h}$ nas profundidades entre 1 a $20 \mathrm{~cm}$. De acordo com os mesmos autores, foram observadas diferenças entre o período chuvoso (inverno) e o seco (verão), sendo que durante a estação seca a temperatura média foi maior e apresentou maior amplitude térmica em função da maior incidência de radiação solar global. Martini et al. (2017) ao verificarem a variação sazonal da temperatura e umidade relativa do ar em remanescentes florestais na cidade de Curitiba, Paraná, registraram uma temperatura média de $21,34^{\circ} \mathrm{C}$ no verão e $12,55^{\circ} \mathrm{C}$ no inverno (variação média de $8,79^{\circ} \mathrm{C}$ ) e umidade relativa do ar média de $83,9 \%$ no verão e $89,7 \%$ no inverno (variação média de $5,8 \%)$. 
De acordo com Mendonça; Danni-Oliveira (2007), nas zonas climáticas equatoriais (54\% do território brasileiro), embora na maior parte do ano o sol esteja mais elevado no horizonte às 12 horas, é por volta das 14 horas que a temperatura máxima do ar será alcançada. Em outras zonas climáticas (tropical e subtropical) localizadas nas porções mais meridionais do Brasil, a sazonalidade térmica é mais expressiva, resultando em variações de temperatura mais extremas ao longo do ano, além de variações nos horários de pico de temperatura durante o dia.

A menor variação das temperaturas do ar e do solo entre a clareira e a mata fechada observada neste estudo durante o inverno, pode ser explicada pelo fato de que a temperatura das áreas com vegetação tem efeito mais forte no resfriamento no verão do que no inverno (CHANG et al., 2007). Em áreas de maior latitude, as clareiras podem apresentar temperaturas menores do que em áreas vegetadas durante o inverno, já que a vegetação irá atuar como uma barreira impedindo que massas de ar mais frias adentrem o interior da floresta e, consequentemente, mantendo uma temperatura mais elevada que a área não vegetada (MAGALHÃES; CRISPIM, 2003). Os resultados obtidos demonstram que a temperatura na clareira se manteve mais alta durante todo o ano, inclusive no inverno, isso porque na área de estudo e em demais regiões equatoriais, a radiação global solar durante o inverno permanece alta, garantindo um maior aquecimento dos solos expostos.

\section{CONCLUSÕES}

Os resultados obtidos neste estudo concluem que áreas com vegetação preservada apresentam um microclima mais estável, com temperaturas do ar e do solo mais amenas e com maior teor de umidade no ar, quando comparadas com áreas sem presença de vegetação arbórea. A fragmentação de hábitats e a abertura de clareiras deve ser evitada já que elevam o perigo de ocorrência de incêndios florestais.

Nos meses mais quentes (Novembro, Dezembro, Janeiro, Fevereiro e Março) foi observado um maior gradiente de variação entre as temperaturas do ar e do solo da mata fechada e da clareira, comprovando o papel da vegetação ter efeito mais forte no resfriamento no verão do que no inverno.

Já que as condições microclimáticas interferem no estabelecimento e sobrevivência da fauna e da flora, recomenda-se que os resultados obtidos sejam utilizados como base para o delineamento de programas de restauração que busquem a inserção e/ou manutenção de populações de espécies ameaçadas na área de estudo.

\section{AGRADECIMENTOS \\ À FAPITEC/SE e ao CNPq pelo apoio financeiro.}

\section{REFERÊNCIAS}

ALVALÁ, R. C. S.; GIELOW, R.; ROCHA, H. R.; FREITAS, H. C.; LOPES, J. M.; MANZI, A. O.; VON RANDOW, C.; DIAS, M. A. F. S.; CABRAL, O. M. R.; WATERLOO, M. J. Intradiurnal and seasonal variability of soil temperature, heat flux, soil moisture content, and thermal properties under forest and pasture in Rondônia. Journal of Geophysical Research: Atmospheres, Hoboken, v. 107, n. D20, p. 10-20, 2002. DOI: https://dx.doi.org/10.1029/2001JD000599

ALVES JÚNIOR, F.; BRANDÃO, C. F. L. S.; ROCHA, K. D.; MARANGON, L. C.; FERREIRA, R. L. C. Efeito de borda na estrutura de espécies arbóreas em um fragmento de floresta ombrófila densa, Recife, PE. Revista Brasileira de Ciências Agrárias, Recife, v. 1, n. 1, p. 49-56, 2006.

BIUDES, M. S.; NOGUEIRA, J. S.; DALMAGRO, H. J.; MACHADO, N. G.; DANELICHEN, V. H. M.; SOUZA, M. C. Mudança no microclima provocada pela conversão de uma floresta de cambará em pastagem no norte do Pantanal. Revista de Ciências Agro-Ambientais, Cáceres, v. 10, n. 1, p. 61-68, 2012.

CARNEIRO, R.; MOURA, M. A. L.; SILVA, V. P. R.; SILVA-JUNIOR, R. S. S.; ANDRADE, A. M. D.; SANTOS, A. B. Variabilidade da temperatura do solo em função da liteira em fragmento remanescente de mata atlântica. Revista Brasileira de Engenharia Agrícola e Ambiental, Campina Grande, v. 18, n. 1, p. 99-108, 2014. DOI: http://dx.doi.org/10.1590/S141543662014000100013

CHANG, C.; LI, M.; CHANG, S. A preliminary study on the local cool-island intensity of Taipei city parks. Landscape and Urban Planning, Amsterdã, v. 80, n. 4, p. 386-395, $2007 . \quad$ DOI: https://dx.doi.org/10.1016/j.landurbplan.2006.09.005

CÔRREA, B. S.; LOUZADA, J. N. C. Bioma cerrado, fragmentação florestal e relações ecológicas com a avifauna. Revista agrogeoambiental, Pouso Alegre, v. 2, n. $3, \quad$ p. 57-72, 2010. DOI: http://dx.doi.org/10.18406/2316-1817v2n32010284

FORTUNIAK, K.; KLYSIK, K.; WIBIG, J. Urban-rural contrasts of meteorological parameters in Lodz. Theoretical and Applied Climatology, Viena, v. 84, p. 91-101, 2006. DOI: https://dx.doi.org/10.1007/s00704005-0147-y

GASPARIM, E.; RICIERI, R. P.; SILVA, S. L.; DALLACORT, R.; GNOATTO, E. Tempera no perfil do solo utilizando duas densidades de cobertura e solo nu. Maringá-PR. Acta Scientiarum Agronomy, Maringá, v. 27, n. 1, p. 107-115, 2005.

HARPER, K. A.; MACDONALD, S. E.; BURTON, P. J.; CHEN, J.; BROSOFSKE, K. D; Saunders, S. C.; EUSKIRCHEN, E. S.; ROBERTS, D.; JAITEH, M. S.; ESSEEN, P. A. Edge influence on forest structure and composition in fragmented landscapes. Conservation Biology, Boston, v. 19, n. 3, p. 768-782, 2005. DOI: https://dx.doi.org/10.1111/j.1523-1739.2005.00045.x

KAPOS, V. Effects of isolation on the water status of forest patches in the Brazilian Amazon. Journal of Tropical Ecology, Cambridge, v. 5, n. 2, p. 173-185, 1989. DOI: https://dx.doi.org/10.1017/S0266467400003448

JÚNIOR, S. S. O microclima de uma vereda degradada: estudo de caso no Parque Estadual Veredas do Peruaçu MG. 140f., 2012. Tese (Doutorado em Geografia) Universidade de São Paulo, São Paulo, 2012.

LAURANCE, W. F.; YENSEN, E. Predicting the impacts of edge effects in fragmented habitats. Biological conservation, Essex, v. 55, n. 1, p. 77-92, 1991. DOI: https://dx.doi.org/10.1016/0006-3207(91)90006-U

MAGALHÃES, L. M. S.; CRISPIM, A. A. Vale a pena plantar e manter árvores e florestas na cidade?. Ciência Hoje, Rio de Janeiro, v. 33, n. 193, p. 64-68, 2003.

MAGURA, T.; LÖVEI, G.L.; TÓTHMÉRÉSZ, B. Edge responses are different in edges under natural versus anthropogenic influence: a meta-analysis using ground 
beetles. Ecology and Evolution, v. 7, n. 3, p. 1009-1017, 2017. DOI: https://dx.doi.org/10.1002/ece3.2722

MARTINELI, L.; SANTOS, E. A.; DE ALMEIDA, R.; ALTOÉ, M.; SANTOS, G. H.; PEZZOPANE, J. E. M. Influência da abertura de clareiras no microclima de Floresta Semidecidual Secundária na bacia do rio Itapemirim, ES. In: ENCONTRO LATINO AMERICANO DE INICIAÇÃO CIENTÍFICA E ENCONTRO LATINO AMERICANO DE PÓSGRADUAÇÃO, 8. e 4., 2004, São José dos Campos. Anais... São José dos Campos: Universidade do Vale do Paraíba, p. 572-575, 2004.

MARTINI, A.; BIONDI, D.; BATISTA, A. C.; DA SILVA FILHO, D. F. Análise microclimática das diferentes tipologias de floresta urbana de Curitiba. Floresta, Curitiba, v. 47, n. 2, p. 137-144, 2017. DOI: http://dx.doi.org/10.5380/rf.v47i2.49518

MENDONÇA, F.; DANNI-OLIVEIRA, I. M. Climatologia: noções básicas e climas do Brasil. São Paulo: Oficina de Texto, 2007. 206 p.

MILAN, A. E.; MORO, R. S. O conceito biogeográfico de ecótono. Terr@Plural, Ponta Grossa, v. 10, n. 1, p. 7588,2016

PEZZOPANE, J. E. M.; REIS, G. D.; REIS, M. D. G. F.; COSTA, J. D. Caracterização da radiação solar em fragmento da Mata Atlântica. Revista Brasileira de Agrometeorologia, Sete Lagoas, v. 13, n. 1, p. 11-19, 2005.

RODRIGUES, B. D.; MARTINS, S. V.; LEITE, H. G. Avaliação do potencial da transposição da serapilheira e do banco de sementes do solo para restauração florestal em área degradada. Revista Árvore, Viçosa, v. 34, n. 1, p. 65-73, 2010. DOI: http://dx.doi.org/10.1590/S010067622010000100008

ROSENZWEIG, M. L. Species diversity in space and time. Cambridge: Cambridge University, 1995. 436 p.

SOARES, R. V.; BATISTA, A. C. Incêndios florestais controle, efeitos e uso do fogo. Curitiba, 2007. 264 p.

TABARELLI, M.; AGUIAR, A. V.; RIBEIRO, M. C.; METZGER, J. P.; PERES, C. A. Prospects for biodiversity conservation in the Atlantic Forest: lessons from aging human-modified landscapes. Biological Conservation, Essex, v. 143, n. 10, p. 2328-2340, 2010 DOI: https://dx.doi.org/10.1016/j.biocon.2010.02.005
WHITE, B. L. A.; OLIVEIRA, M. V. N.; RIBEIRO, G. T. Avaliação e simulação do comportamento do fogo em diferentes fitofisionomias de uma área de Mata Atlântica do Nordeste Brasileiro. Floresta, Curitiba, v. 47, n. 3, p. 247-256, 2017.

DOI: http://dx.doi.org/10.5380/rf.v47i3.50844

WHITE, B. L. A.; RIBEIRO, A. S. Análise da eficiência dos índices de perigo de ocorrência de incêndios florestais para o Parque Nacional Serra de Itabaiana, Sergipe. In: SANTOS, A. C.; FILHO, J. D.; SOARES, M. J. N.; RANDOW, P. C. B. D. (Orgs.). Pensar a (in)sustentabilidade: desafios à pesquisa. Porto Alegre: Redes Editora, 2010. p. 197-209.

WHITE, B. L. A.; RIBEIRO, A. S. Análise da precipitação e sua influência na ocorrência de incêndios florestais no Parque Nacional Serra de Itabaiana, Sergipe, Brasil. Ambiente \& Água, Taubaté, v. 6, n. 1, p. 148-156, 2011. DOI: http://dx.doi.org/10.4136/ambi-agua. 180

WHITE, B. L. A.; RIBEIRO, G. T.; SOUZA, R. M. Caracterização do material combustível e simulação do comportamento do fogo em eucaliptais no litoral norte da Bahia, Brasil. Floresta, Curitiba, v. 44, n. 1, p. 33 - 42, 2014. DOI: http://dx.doi.org/10.5380/rf.v44i1.32977

WHITE, B. L. A.; WHITE, L. A. S.; RIBEIRO, G. T.; FERNANDES, P. M. A. Development of a fire danger index for Eucalypt plantations in the Northern Coast of Bahia, Brazil. Floresta, Curitiba, v. 43, n. 4, p. 601-610, 2013. DOI: http://dx.doi.org/10.5380/rf.v43i4.30973

WHITE, B. L. A.; WHITE, L. A. S.; RIBEIRO, G. T.; SOUZA, R. M. Empirical models for describing fire behavior in Brazilian commercial eucalypt plantations. CERNE, Lavras, v. 22, n. 4, p. 397-406, 2016. DOI: http://dx.doi.org/10.1590/01047760201622042227

WHITE, L. A. S.; WHITE, B. L. A.; RIBEIRO, G. T. Evaluation of forest fire danger indexes for eucalypt plantations in Bahia, Brazil. International Journal of Forestry Research, v. 2015, 2015. DOI: http://dx.doi.org/10.1155/2015/613736 